\title{
Real-Scale Fire Wind Tunnel Experiment on Generation of Firebrands from a House on Fire
}

\author{
Hideki Yoshioka ${ }^{1}$, Yoshihiko Hayashi ${ }^{2}$, Hideaki Masuda ${ }^{2}$ and Takafumi Noguchi ${ }^{1}$ \\ ${ }^{1}$ The University of Tokyo, Japan \\ ${ }^{2}$ Building Research Institute, Japan
}

\begin{abstract}
Factors that cause spreading of urban fires among buildings are flame contact, radiant heat, convective heat, and firebrands. There are many cases in which firespread is caused by leaping flames resulting from many firebrands in places that are distant from the fire outbreak site, especially under strong wind conditions. Firebrands and leaping flames caused by them are important factors to clarify the mechanism of urban fires. Nevertheless, their systematic engineering study has not been greatly implemented because of limited availability of experimental facilities.

Therefore, the authors performed a Fire Wind Tunnel experiment using a real-scale fire preventive wooden house to investigate firebrands. This study is aimed at quantitatively and qualitatively elucidating the chronological relationship of fire evolution and firebrand generation.
\end{abstract}

keywords : firebrand, urban fire, strong wind, Fire Wind Tunnel, real-scale fire experiment

\section{INTRODUCTION}

Tests were performed at Fire Wind Tunnel (Photo 1) at Building Research Institute. A wood crib (Photo 2) arranged to the upwind of the specimen house was ignited after a predetermined wind velocity was reached. Thereby, a fire at an adjacent building upwind was reproduced. However, the crib burned out without causing spread to the test house. Forced ignition was carried out in the house. The image, wind velocity, temperature, heat flux, and mass change of the house were recorded during the experiment. In addition, firebrands were collected and measured after completion of the experiment. We used these data to comprehend the fire evolution status and generation of firebrands as accurately as possible. 


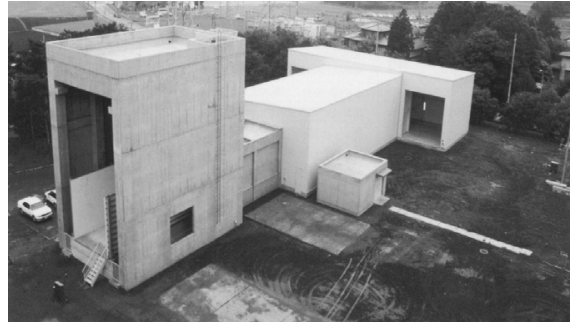

Photo 1 Overview of Fire Wind Tunnel [1].

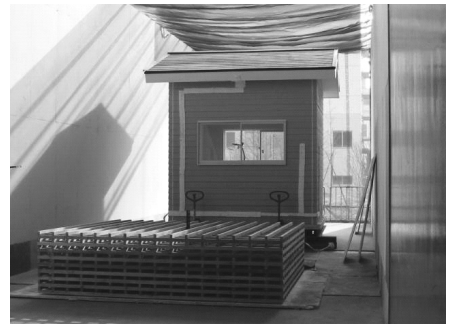

Photo 2 Wood crib and specimen house.

\section{ACTUAL SIZE EXPERIMENT IN FIRE WINDTUNNEL}

\subsection{Experimental facilities}

The wood crib, house, and brand collection trays were set as shown in Figure 1. The wood crib was placed at $3 \mathrm{~m}$ upwind from the house. Wood crib dimensions were $2.85 \times$ $2.85 \mathrm{~m}$ - the same size as the house. Two $1 \times 1 \mathrm{~m}$ trays were prepared and placed $2 \mathrm{~m}$ downwind from the house from east to west. One tray was wetted with water to deter combustion of fallen firebrands and to maintain their shape. The other tray was emptied to compare how far a firebrand burns. Hereinafter, the trays are referred to as "wet" and "dry", respectively.

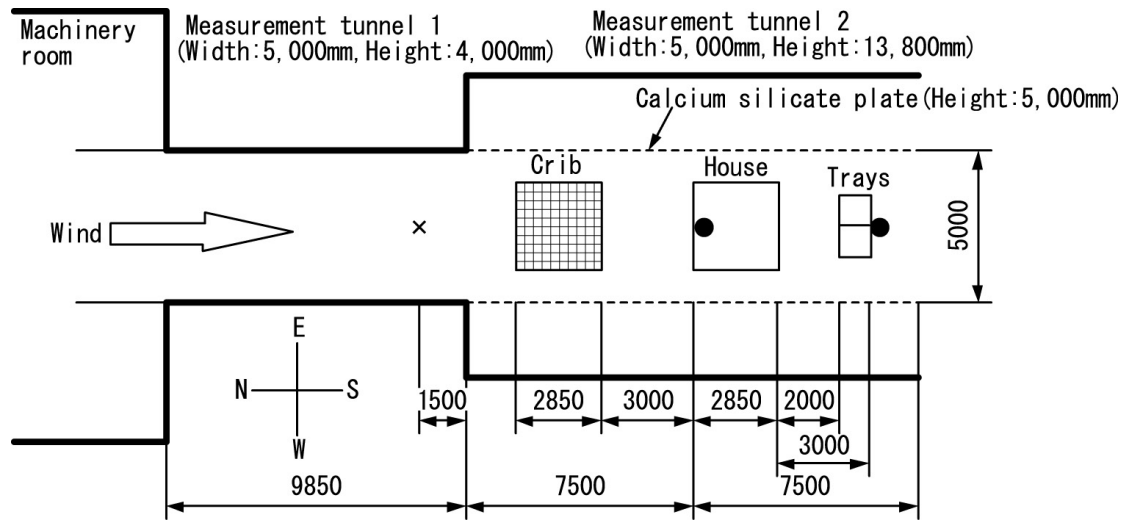

Figure 1 Layout in Fire Wind Tunnel (unit: $\mathrm{mm}$ ).

\subsection{Measured items}

Ten miniature CCD cameras were installed in Fire Wind Tunnel. Combustion of the wood crib and house and the generation of firebrands were recorded from various positions. A hot-wire anemometer (a typical anemometer) was installed $1.5 \mathrm{~m}$ upwind from the border of the measurement tunnel at a height of $1.5 \mathrm{~m}$ above the floor level ( $\mathrm{x}$ in Figure 1) to measure influx wind velocity. Thermocouples were installed at seven 
points on the wood crib around the perimeter and at the center. They were also at 58 points around the house: at each member of the wooden frame, inside and outside the walls, on the eaves, in the attic, and in spaces inside and outside the house. Heat flux transducers were installed inside the north opening of the house and to the south of the tray (solid circles in Figure 1) to measure incident heat by fire in the adjacent building. Load cells were installed beneath the house to measure its mass loss history.

\subsection{Experimental conditions}

The specimen house is fire preventive wooden (with outer wall siding and slate roofing). Figures 2 and 3 show its sectional view and its plane view, respectively. Figure 4 shows the layout of combustibles in the room. They are listed in Table 1. The mass of the combustibles per unit area is $30 \mathrm{~kg} / \mathrm{m}^{2}$. Solid circles in Figures 2 and 3 indicate the thermocouple installation points. The wood crib consists of 18 layers crossing each other. Each layer comprises 17 unit Scotch pine components of $30 \times 40 \times 2,850 \mathrm{~mm}$ placed in parallel. Its height is $720 \mathrm{~mm}$ and total mass is about $613 \mathrm{~kg}$. The wood crib was ignited under a wind velocity of $2 \mathrm{~m} / \mathrm{s}$. The wind velocity then increased by a winding flow accompanying crib combustion (Figure 5). Although the wind velocity was changed to 4 $\mathrm{m} / \mathrm{s}$ at 13 ', the crib was mostly burned out at 20' after not igniting the house. A plastic garbage can was placed at the northeast corner in the room at 20'45", and newspaper in the can was ignited (Figure 4).

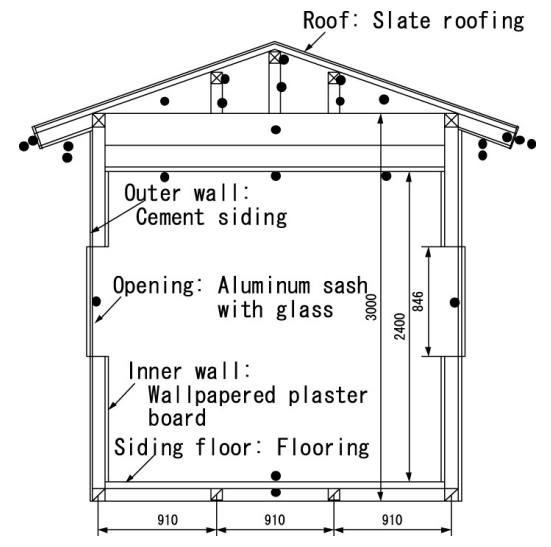

Figure 2 Sectional view of specimen house (unit: $\mathrm{mm}$ ).

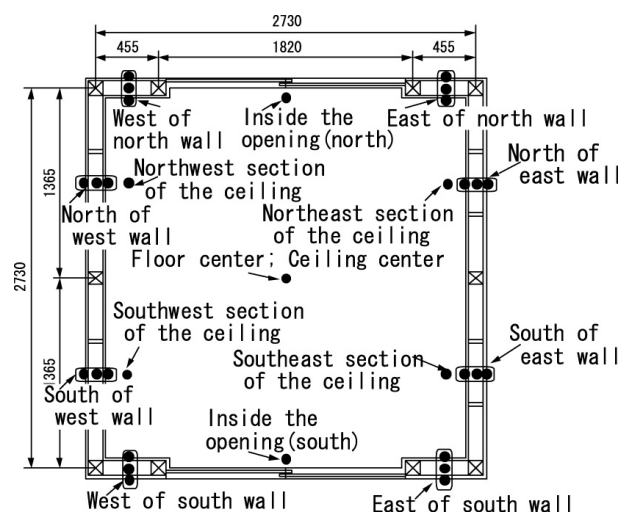

Figure 3 Plane view. 


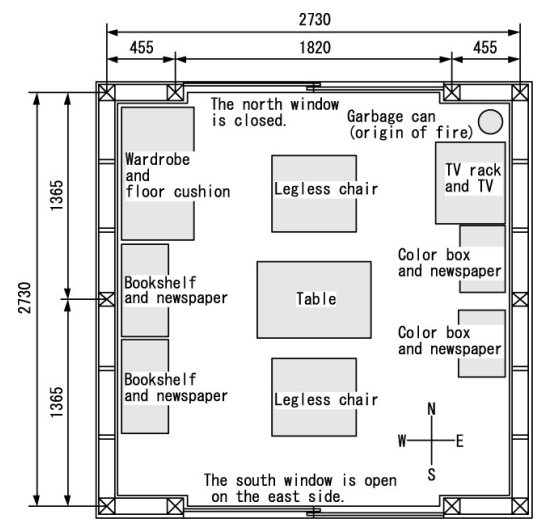

Table 1 List of combustibles.

\begin{tabular}{|l|l|r|r|r|}
\hline Combustible & $\begin{array}{c}\text { Dimensions } \\
(\mathrm{W} \times \mathrm{D} \times \mathrm{H}(\mathrm{mm}))\end{array}$ & Number & Weight $(\mathrm{kg})$ & Material \\
\hline TV & $358 \times 355 \times 323$ & 1 & 8.165 & plastic \\
\hline TV rack & $530 \times 450 \times 433$ & 1 & 9.223 & wood \\
\hline Color box & $430 \times 294 \times 870$ & 2 & 14.402 & plastic \\
\hline Folding table & $750 \times 500 \times 330$ & 1 & 6.956 & wood \\
\hline Legless chair & $550 \times 500 \times 600$ & 2 & 5.703 & nylon \\
\hline Wardrobe & $867 \times 465 \times 878$ & 1 & 30.219 & wood \\
\hline Floor cushion & $550 \times 590$ & 4 & 3.860 & nylon \\
\hline Bookshelf & $610 \times 294 \times 1782$ & 2 & 31.084 & wood \\
\hline Newspaper & & 113.975 & paper \\
\hline \multicolumn{2}{|c|}{ Total weight $(\mathrm{kg})$} & & 223.587 & \\
\hline
\end{tabular}

Figure 4 Layout of combustibles in the room.

\section{CHRONOLOGICAL RELATIONSHIP BETWEEN FIRE PROGRESS AND OUTBREAK OF FIREBRANDS}

\subsection{Experimental results}

Photos 3 and 4 and Figures 5-8 show temperature, wind velocity, incident heat flux, and the mass change of the house. The time origin was set at the moment of crib ignition. The incident heat flux at the north opening of the house reached the maximum, 18.6 $\mathrm{kW} / \mathrm{m}^{2}$, at 10' (Photo 3, Figure 7). The firing limit of wood was exceeded momentarily. And newspaper in the can was ignited at the northeast corner in the room (Figure 4) at $20^{\prime} 45^{\prime \prime}$. It lit and fire gradually spread; flashover occurred at 50' (29'15" after ignition in the room). The room temperature rose rapidly to reach around $800^{\circ} \mathrm{C}$ (Figure 6), and jet flame came out of an opening at 55' (Photo 4). This temperature was maintained until the house started to collapse at $80^{\prime}$. Figure 8 indicates that the mass change of the house for $50^{\prime}-80^{\prime}$ was $710.2 \mathrm{~kg}$. The mass loss rate of the burning house is estimated below:

$$
\frac{710.2}{(30 \times 60) \times 2.73^{2}} \approx 0.05\left(\mathrm{~kg} / \mathrm{m}^{2} \cdot \mathrm{sec}\right)
$$

This equation provides a value a little lower than the previous survey-result [2]. The initial mass of the house was about $2,329 \mathrm{~kg}$.

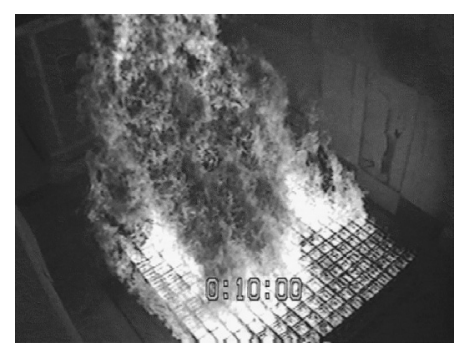

Photo 3 Wood Crib (10').

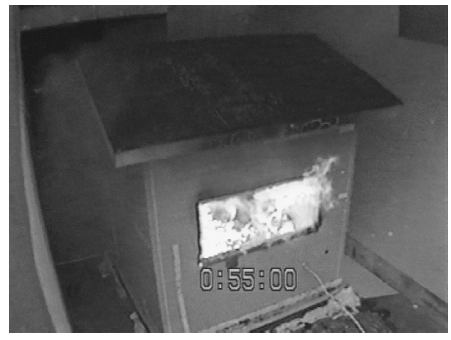

Photo 4 Ejected flame out of an opening (55'). 


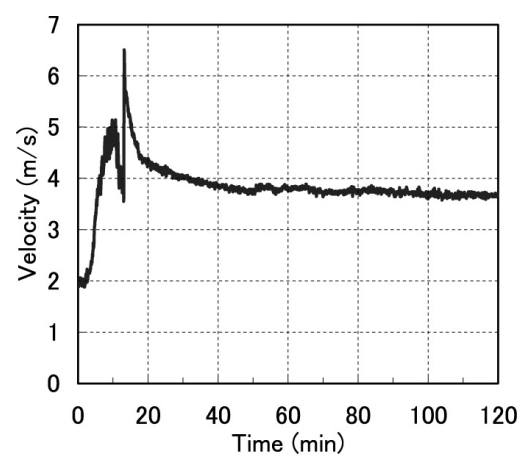

Figure 5 Wind velocity.

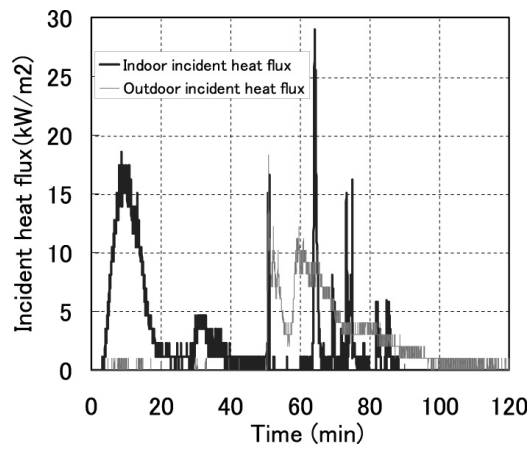

Figure 7 Incident heat flux.

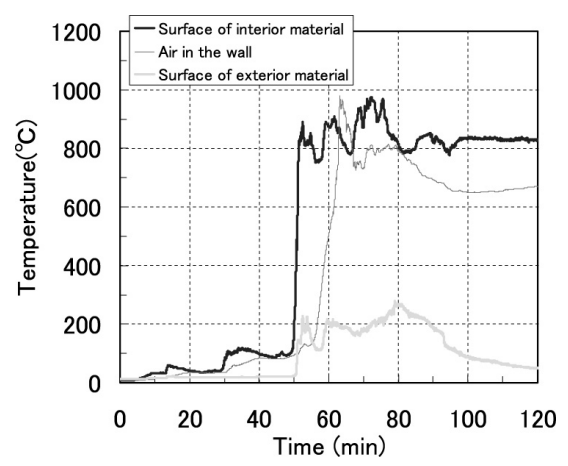

Figure 6 Temperature on the western part of south wall.

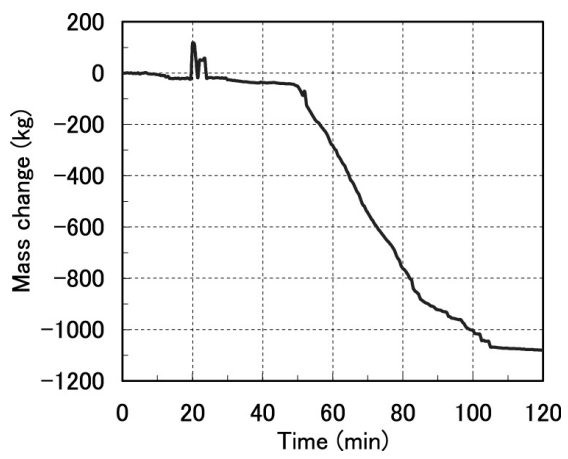

Figure 8 Mass change of the house.

\subsection{Estimation of Fire Progress}

Fire evolution was inferred based on the above-mentioned experimental result. Table 2 describes details; Figure 9 depicts the fire evolution in the house.

Table 2 Status of fire evolution.

\begin{tabular}{|l|l|}
\hline Time & Status of fire evolution \\
\hline $0^{\prime}$ & The wood crib is ignited (wind velocity: $2 \mathrm{~m} / \mathrm{s}$ ). \\
\hline $13^{\prime}$ & The wind velocity is increased to $4 \mathrm{~m} / \mathrm{s}$ and unchanged thereafter. \\
\hline $20^{\prime}$ & The wood crib is mostly burned out. \\
\hline $20^{\prime} 45^{\prime \prime}$ & A garbage can at the northeast corner in the room is ignited. \\
\hline $21^{\prime} 50^{\prime \prime}$ & Some newspaper is added to the can. \\
\hline $22^{\prime} 55^{\prime \prime}$ & Addition of newspaper is stopped. \\
\hline $29^{\prime}$ & Flame starts to expand in the room. \\
\hline $29^{\prime} 30^{\prime \prime}$ & The color box on the southeast starts to burn. \\
\hline $30^{\prime}$ & Black smoke occurs from the south opening. \\
\hline $49^{\prime} 45^{\prime \prime}$ & The floor and table start to burn. \\
\hline $49^{\prime} 55^{\prime \prime}$ & The footing of the bookshelf on the west side starts to burn. \\
\hline $50^{\prime}$ & $\begin{array}{l}\text { Flame goes up along the bookshelf at a stretch to the ceiling;flashover } \\
\text { occurs. }\end{array}$ \\
\hline
\end{tabular}




\begin{tabular}{|l|l|}
\hline $55^{\prime}$ & Jet flame occurs from the south opening (Photo 4). \\
\hline $60^{\prime}$ & Flame penetrates the ceiling and reaches the short pillar and the roof. \\
\cline { 2 - 2 } & Jet flame on the south is expanded. \\
\hline $65^{\prime}$ & Jet flame on the south reaches the eaves and the roof. \\
\hline $75^{\prime}$ & Fire begins to penetrate the roof. \\
\hline \multirow{3}{*}{$80^{\prime}$} & The house begins to collapse. \\
\cline { 2 - 3 } & The eaves, the wall above the opening and the roof on the south collapse. \\
\cline { 2 - 3 } & The wall above the opening and the roof on the north collapse. \\
\hline \multirow{2}{*}{$5^{\prime}$} & The wall below the opening on the south also collapses. \\
\cline { 2 - 3 } & Eaves collapse on the north. \\
\hline \multirow{3}{*}{$100^{\prime}$} & The south side of west wall begins to collapse. \\
\hline $105^{\prime}$ & Slate roofing collapses completely. \\
\cline { 2 - 3 } & The rafters at the southeast and southwest ends collapse. \\
\cline { 2 - 3 } & The rafters at the northeast and northwest ends still survive. \\
\hline & The rafters at the northeast and northwest ends also collapse. \\
\hline
\end{tabular}

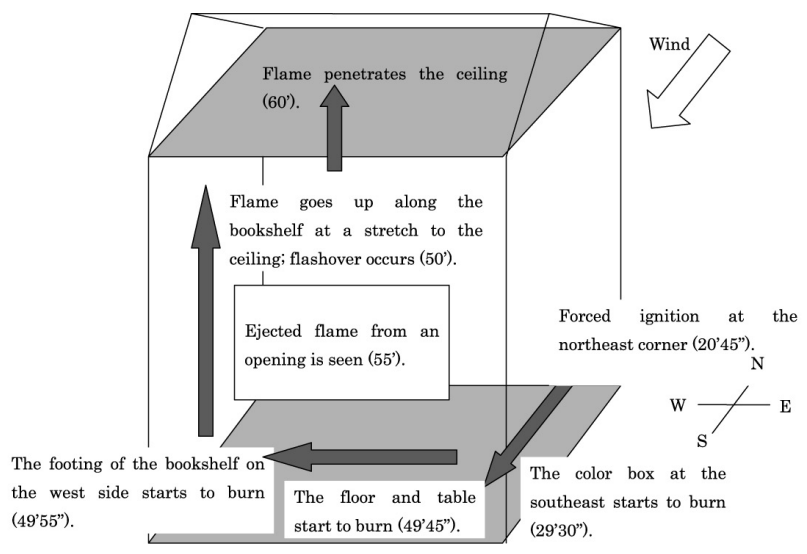

Figure 9 Fire evolution in the house.

\subsection{Information on Firebrands Collected in Trays}

\subsubsection{Size classification and mass measurement}

Firebrands generated from the burning house were divided roughly into two types: charcoal type and ash type. We measured the size and mass of the charcoal-type firebrands. First, the firebrand size was classified based on its projected area stably placed on a horizontal plane. Table 3 shows the number and the total mass for each class for wet and dry trays. Photo 5 shows the appearance of firebrands (small) on a $5 \mathrm{~cm}$ grid. The mass of charcoal-type firebrands was measured to compute their mean, variance, and standard deviation. Table 4 shows all results for each tray and each class. 
Table 3 Number and total mass for each class.

\begin{tabular}{|c|c|c|c|c|c|}
\hline \multirow[t]{2}{*}{ Class } & \multirow[t]{2}{*}{ Area $\left(\mathrm{cm}^{2}\right)$} & \multicolumn{2}{|c|}{ Number } & \multicolumn{2}{|c|}{$\begin{array}{l}\text { Total mass for } \\
\text { each class }(\mathrm{g})\end{array}$} \\
\hline & & Wet & Dry & Wet & Dry \\
\hline Large & $\mathrm{S} \geqq 4$ & 1 & 4 & 0.325 & 1.092 \\
\hline Medium & $2 \leqq S<4$ & 15 & 10 & \begin{tabular}{|l|}
1.620 \\
\end{tabular} & 1.440 \\
\hline Small & $1 \leqq \mathrm{~S}<2$ & 44 & 15 & \begin{tabular}{|l|}
1.672 \\
\end{tabular} & 0.750 \\
\hline Fine & $0.25 \leqq \mathrm{~S}<1$ & 308 & 33 & \begin{tabular}{|l|}
2.772 \\
\end{tabular} & 0.561 \\
\hline & otal & 368 & 62 & 6.389 & 3.843 \\
\hline
\end{tabular}

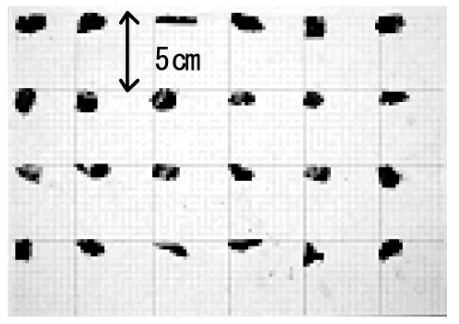

Photo 5 Firebrands (small).

Table 4 Mass per firebrand.

\begin{tabular}{|l|r|r|r|r|r|r|r|r|}
\hline & \multicolumn{2}{|c|}{ Large } & \multicolumn{2}{c|}{ Medium } & \multicolumn{2}{c|}{ Small } & \multicolumn{2}{c|}{ Fine } \\
\cline { 2 - 9 } & Wet & Dry & Wet & Dry & Wet & Dry & Wet & \multicolumn{1}{c|}{ Dry } \\
\hline Mean (g) & 0.325 & 0.273 & 0.108 & 0.144 & 0.038 & 0.050 & 0.009 & 0.017 \\
\hline Max. (g) & 0.325 & 0.412 & 0.266 & 0.245 & 0.076 & 0.125 & 0.061 & 0.052 \\
\hline Min. (g) & 0.325 & 0.087 & 0.049 & 0.058 & 0.012 & 0.021 & 0.001 & 0.004 \\
\hline Variance & 0.000 & 0.019 & 0.003 & 0.004 & 0.0003 & 0.001 & 0.000057 & 0.00011 \\
\hline S.D. & 0.000 & 0.138 & 0.053 & 0.060 & 0.0163 & 0.025 & 0.007549 & 0.01039 \\
\hline Number & 1 & 4 & 15 & 10 & 44 & 15 & 308 & 33 \\
\hline
\end{tabular}

\subsubsection{Comparison of firebrands (wet tray and dry tray)}

Table 3 indicates that the total number of firebrands in the wet tray is about six times greater than that in the dry tray (wet: 368 , dry: 62). Comparison of numbers in each class indicates that the relative ratio of smaller firebrands increases in the wet tray. Especially, 80\% or more of all firebrands in the wet tray were "fine", whereas only about 50\% were so in the dry tray. It is inferred that many fine firebrands were blown away after landing; alternatively, they burned out and disappeared. Table 3 shows that the total mass of firebrands in the wet tray exceeds that in the dry tray: $6.389 \mathrm{~g}$ (wet) > $3.843 \mathrm{~g}$ (dry). Firebrands in the wet tray are larger in every class, except for the "large" class.

The mass per piece in the dry tray is greater than in the wet tray for every class except "large", as shown in Table 4. In short, for "medium" or smaller firebrands, the total mass for every class is larger in the wet tray, whereas the mass per piece is greater in the dry tray.

\subsection{Correspondence between Fire Evolution and Firebrand Generation}

The increment in the number of firebrands (both charcoal type and ash type) in a quarter of each tray was counted visually based on video images. Figure 10 shows the result. The first increment began at 35'. This is considered to result from black smoke issuing from the south opening at $30^{\prime}$. The next increment took place rapidly at 55 '. This is inferred to be the result of ash-type firebrands that originated from combustibles and floated in the room, then blown outside in the blast at flashover that took place at 50'. 
The gentle increase after 60' is assumed to have occurred from the increase of charcoal type firebrands that originated from the wooden frame. An incremental increase in firebrands was observed particularly when the house started to collapse and fire started to penetrate the roof. Tables 5 and 6 show the correspondence between the generation of firebrands in each tray and details of fire evolution. The increment of firebrands in the table is the relative value to the number of firebrands counted 5 ' before.

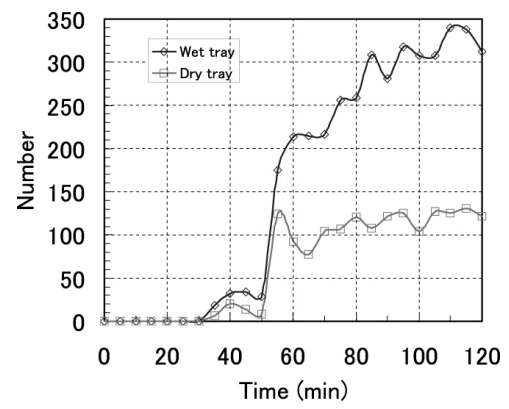

Figure 10 The number of firebrands in the trays.

Table 5 Correspondence between firebrand generation and fire evolution (wet tray).

\begin{tabular}{|r|r|r|l|}
\hline \multicolumn{2}{|c|}{ Firebrand generation } & \multicolumn{2}{|c|}{ Fire evolution } \\
\hline \multicolumn{1}{|c|}{ Time } & Increment & Time & Possible cause \\
\hline $55^{\prime}$ & 146 & $50^{\prime}$ & Flashover occurs. \\
\hline $85^{\prime}$ & 50 & $80^{\prime}$ & The house starts to collapse. \\
\hline $75^{\prime}$ & 40 & $75^{\prime}$ & Fire starts to penetrate the roof. \\
\hline $60^{\prime}$ & 39 & $55^{\prime}$ & Jet flame occurs from the south opening. \\
\hline $95^{\prime}$ & 37 & $90^{\prime}$ & The west wall starts to collapse on the south side. \\
\hline $110^{\prime}$ & 32 & $105^{\prime}$ & Rafters on the northeast and northwest ends collapse. \\
\hline $35^{\prime}$ & 18 & $30^{\prime}$ & Black smoke issues from an opening. \\
\hline
\end{tabular}

Table 6 Correspondence between firebrand generation and fire evolution (dry tray).

\begin{tabular}{|r|r|r|l|}
\hline \multicolumn{2}{|c|}{ Firebrand generation } & \multicolumn{2}{|c|}{ Fire evolution } \\
\hline \multicolumn{1}{|c|}{ Time } & Increment & Time & Possible cause \\
\hline $55^{\prime}$ & 116 & $50^{\prime}$ & Flashover occurs. \\
\hline $70^{\prime}$ & 27 & $65^{\prime}$ & Jet flame reaches the roof. \\
\hline $105^{\prime}$ & 23 & $100^{\prime}$ & Rafters on the southeast and southwest ends collapse. \\
\hline
\end{tabular}

\section{CONCLUSION}

A chronological relationship between firebrand generation and fire evolution was elucidated by a real-scale fire experiment. Events in fire evolution which promote firebrand generation include: the outbreak of flashover, which is characterized by ejected flames from openings; and degradation of components including roof, walls, and rafters. 
Firebrands generated from a fire preventive wooden house on fire under wind were collected after the experiment. Their shapes and masses were measured precisely.

\section{FUTURE PROSPECTS}

Based on these results, subsequent Fire Wind Tunnel experiments should be conducted with conditions such as wind velocity, structure, and combustibles as variables. Thereby, the effects of different conditions for generation of firebrands can be compared and studied.

To comprehend the fire propagation nature of firebrands more definitely, the collected firebrands will be analyzed in greater detail. Furthermore, real-scale and model experiments will be carried out to investigate the scattering nature and ignitability.

\section{ACKNOWLEDGEMENTS}

A portion of this study was supported by Grants-in-Aid for scientific research (Fundamental research (B), Research representative: Y. Hayashi, Theme number: 14350332) from the Ministry of Education, Culture, Sports, Science and Technology in fiscal year 2002 .

\section{REFERENCES}

1. Y. Hayashi, M. Yoshida, T. Kinoshita, Y. Misawa, T. Osaki, T. Wakamatsu, and T. Saga: Fundamental ability of Fire Wind Tunnel at Building Research Institute and Experimental Results Therewith, Journal of Japan Association for Wind Engineering, No. 86, January, 2001, pp. 55-74 (in Japanese)

2. M. Sekito, K. Koshiyama, A. Hokugo, and M. Murozaki: Mass burning rate estimation in city fire, Proceedings of Annual Conference of the Architectural Institute of Japan Academic Lecture in 2000, pp.191-194 (in Japanese). 